\title{
Conhecer para entender: um estudo observacional da geomorfologia costeira de Santa Catarina
}

\section{Knowing to understand: an observational study of the coastal geomorphology of Santa Catarina}

Felipe Rodrigues ${ }^{*}$, Ana Paula de Martini de Souza ${ }^{1}$, Tairiny Simeonato², Ronaldo Alves dos Santos Junior², Ana Beatriz de lima Neves Gonzaga², Fabiola Kaviatkovski² 1- Instituto Oceanográfico da Universidade de São Paulo, Program. Pós-Grad. Oceanografia - E-mall:Feliperodrigues@usp.br, anamartini@usp.br

2-Centro de Estudos do Mar, Universidade Federal do Paraná.E-mall:talimeonato@gmall.com, E-mall: rasj.ronaldo@gmall.com, neveslbea@gmall.com, FABIOLAA.oC@GMAL.COM

Abstract: The coastal zone is an area of considerable economic importance due to tourism, fishing and port activities. These scenarios compounded with rapid urban growth require the application of environmental mitigation policies, such as sustainable environmental zoning to reduce the degradation of coastal zones. This study aims to contextualize Santa Catarina's geomorphological coastal features by means of field observations using scientific photography in six selected municipalities. Coastal dynamics, including weathering processes, transport agents, and the deposition of sedimentary material, have influenced the local geomorphology at all assessed locations. The authors have observed several beach environments with erosion damages, as well as some techniques being used to contain these processes. In conclusion, observational studies are important to improve the understanding of coastal environments evolution and to provide data for coastal management and environmental zoning.

\section{Manuscrito:}

Recebido: 12/out/16

Corrigido: 27/nov/17

Aceito: $14 / \mathrm{fev} / 18$

Citation: Rodrigues F., Souza A.P.M., Simeonato T., Santos Junior R.A, Gonzaga A.B.LN., Kaviatkovski F. 2018. Conhecer para entender: um estudo observacional da geomorfologia costeira de Santa Catarina. Terræ Didatica, 14(2):109-118. URL: http://www.ige.unicamp. br/terraedidatica/.

Keywords: Coastal zone, Geomorphology, Field Observations, Santa Catarina, Coastal Management.

\section{Introdução}

O litoral brasileiro compreende uma faixa que se estende por mais de $8.500 \mathrm{~km}$ voltados para o Oceano Atlântico, com aproximadamente 9.250 $\mathrm{km}^{2}$ de área costeira, concentrando um quarto da população e 70\% do PIB do país (Muehe 2006). No país, o turismo é uma das atividades econômicas mais rentáveis, com destaque para a região Nordeste e o Estado de Santa Catarina, na região Sul (Beker 2006). Porém, apesar de sua extrema importância econômica, o turismo e a intensa ocupação da zona costeira ocorreram de forma desordenada, criando conflitos de zoneamento com outras atividades, como portos, pesca e aquicultura. Em concordância, atualmente, o litoral de Santa Catarina encontra-se sob grande pressão das atividades antrópicas, fazendo-se necessária a aplicação de políticas de mitigação e zoneamento ambiental (Pereira 2003, MMA 2006, Chaves 2017).

As zonas costeiras são ambientes que estão em constante transformação em diversas escalas temporais e espaciais, podendo, em alguns casos, ser observadas na escala de tempo humana. Assim, as alterações antrópicas, tais como mudanças no contorno praial, engordas de praia e entre outros, fragilizam a rápida dinâmica existente nesses ambientes (Bessa et al. 2014) e podem ser observadas em uma escala de anos. Portanto, o conhecimento prévio da região e o monitoramento ambiental tornam-se mecanismos de suma importância para o entendimento da dinâmica costeira e da gestão destes ambientes, se tornando assim, instrumentos indispensáveis para o manejo e desenvolvimento da zona costeira (Ruggiero et al. 2000, Mills et al. 2005).

A faixa litorânea passa por processos naturais de remoção e acreção de sedimentos que contribuem para a formação e desenvolvimento das linhas de costa; no entanto, a intensificação das atividades humanas na zona costeira acelera os processos, impactando principalmente as propriedades localizadas próximas ao ambiente praial (Lins-de-Barros 2005, Souza 2009, Rijn 2011).

Em função dos constantes processos naturais e mudanças antrópicas, o profundo conhecimento 
das feições geomorfológicas com base em sua gênese, aporte, dinâmica sedimentológica e influências antrópicas é fundamental para tomadas de decisões voltadas à gestão costeira (Reis 2013). Neste contexto, é imprescindível conhecer como os processos costeiros atuam em cada região e quais os fatores que controlam os mesmos, a fim de conseguir compreender a complexidade do ambiente que se deseja estudar, empreender, zonear ou mesmo restaurar. Isto posto, o presente estudo tem como objetivo contextualizar as feições geomorfológicas do litoral de Santa Catarina, com base em sua gênese, aporte, dinâmica sedimentológica e influências antrópicas vistas em campo, com a finalidade de ressaltar a importância de se conhecer o ambiente costeiro, antes que qualquer atividade venha a ser executada.

\section{Metodologia}

Embora a observação de campo seja considerada pré-requisito para qualquer estudo geológico ou geomorfológico, não existe uma metodologia bem definida para estes estudos observacionais (Rhodes e Thron 1996, Fookes et al. 2000). Deste modo, para a realização deste trabalho, foram adaptadas metodologias de ensino no qual, cada ambiente do litoral catarinense (ponto) foi abordado como um estudo de caso a ser discutido entre os membros.

\section{Área de Estudo}

Localizado na região sul do Brasil, entre $26^{\circ}$ a $29.3^{\circ} \mathrm{S}$, o Estado de Santa Catarina possui $564 \mathrm{~km}$ de extensão. Sua planície costeira, com menos de $20 \mathrm{~km}$ de largura, se estende das fácies praiais às Escarpas da Serra do Mar e dos Campos Gerais que dividem o estado entre uma região de planalto a oeste e a planície litorânea a leste (Bortoluzzi 1987, Short \& Klein, 2016) (Fig. 1), onde são desenvolvidas atividades econômicas de grande importância para o Estado, como a atividade turística, portuária e pesqueira (Rodrigues et al. 2004).

De acordo com a classificação de Köppen, Santa Catarina possui um clima mesotérmico úmido sem estações secas (-Cf), abrangendo também o clima oceânico (Cfa e Cfb) (Pellegrin, José e Vendelino 2014). Devido à sua localização e relevo, aliados à atuação da Massa de ar Polar Atlântica e da Massa Tropical Atlântica, Santa Catarina apresenta uma distribuição pluviométrica regular durante o ano, com uma média de cerca de $1500 \mathrm{~mm} / \mathrm{ano}$ (Andrade, Baro e Nery 1999; Porto Filho 1993), sendo os maiores índices de precipitação observados próximo à encosta da Serra Geral. Nos municípios litorâneos, o inverno é a estação com menor volume de precipitação, refletindo em condições de tempo mais estáveis. Observa-se um notável efeito latitudinal na temperatura, resultando temperaturas mais altas no litoral norte e um declínio gradual em direção ao litoral sul (Monteiro 2001). A temperatura média anual alcança os $20^{\circ} \mathrm{C}$, com média mensal de aproximadamente $23^{\circ} \mathrm{C}$ durante o verão e $17^{\circ} \mathrm{C}$ no inverno (Andrade, Baro e Nery 1999; Porto Filho 1993). A Ilha de São Francisco do Sul (SFS) $\left(26^{\circ} \mathrm{S}-48^{\circ} \mathrm{W}\right)$ está localizada no litoral norte de Santa Catarina, adjacente à Baía da Babitonga. A ilha é formada por uma extensa planície costeira, na qual as feições geomorfológicas são evidências de processos costeiros transcorridos ao longo do Quaternário (Possamai et al. 2011). Além disso, o sul da ilha é delimitado pelo Canal do Linguado. A construção do aterro da BR-280, na década de 30, fez com que houvesse a oclusão desse canal, interrompendo os fluxos hidrodinâmicos no setor interno da baía. Tais mudanças resultaram em alterações nos processos sedimentares deste estuário (Vieira et al. 2008).

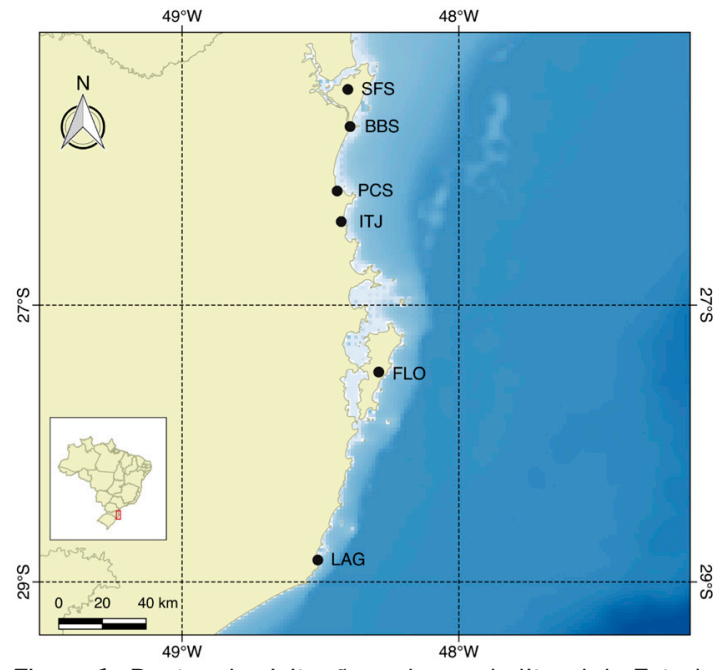

Figura 1. Pontos de visitação ao longo do litoral do Estado de Santa Catarina destacados em círculos petros, sendo: SFS - São Francisco do Sul; BBS - Balneário Barra do Sul; PCS - Piçarras; ITJ - Itajaí; FLO Florianópolis e LAG - Laguna

A criação do Canal do Linguado ampliou a taxa de sedimentação no Balneário Barra do Sul (Fig. 1- BBS) $\left(26^{\circ} \mathrm{S}-48^{\circ} \mathrm{W}\right)$, resultando em um aumento da urbanização sobre esses sedimentos inconsolidados (Vieira et al. 2008). No entanto alta incidência de ondas provocou problemas de erosão 
praial na Barra do Sul. A fim de conter o processo erosivo, enrocamentos perpendiculares à linha de costa foram implantados ao longo do perfil praial (Muehe 2006).

O mesmo vem ocorrendo no Balneário Piçarras (Fig. 1 - PCS), situado no litoral centro-norte de Santa Catarina $\left(26^{\circ} \mathrm{S}-48^{\circ} \mathrm{W}\right)$, o qual passou a apresentar um perfil erosivo nos últimos anos, responsável por prejuízos econômicos e ambientais no município. Espigões rochosos foram construídos com a intenção de reduzir a quantidade de areia retirada pelas correntes e ondas marinhas (Araújo et al. 2010) As alterações na dinâmica deste ambiente estão associadas à intensa urbanização da zona litorânea, como a interrupção do sistema dunar da região e modificações na curvatura do perfil praial ocasionados pelo arruamento (Muehe 2006).

O município de Itajaí (Fig. 1 - ITJ) $\left(26^{\circ} \mathrm{S}\right.$ - 48 $\mathrm{W}$ ), localizado na desembocadura do Rio Itajaí-Açu, apresenta intensa atividade portuária e pesqueira. Para a manutenção do Porto de Itajaí, foi necessária a ampliação na largura do canal de acesso ao porto para que o mesmo se mantivesse estável entre os dois molhes de contenção (norte e sul) que foram construídos. Os quais, tornaram o canal mais retilíneo e melhor para a navegação (Schettini 2002), causando conflitos de zoneamento com outras atividades, principalmente a pesqueira.

Já em Florianópolis (Fig. 1 - FLO) $\left(27^{\circ} \mathrm{S}-\right.$ $\left.48^{\circ} \mathrm{W}\right)$, a capital do Estado de Santa Catarina, as praias arenosas apresentam sedimentos com granulometria de médio a fino. Além disso, também há a presença de dois campos dunares: Aranhas e Joaquina. Tanto as praias quanto os campos dunares estão sob intenso processo de urbanização devido ao crescimento da capital e concentração do turismo na região (Oliveira 2009).

No litoral sul de Santa Catarina, o município de Laguna (Fig. 1 - LAG) $\left(28^{\circ} \mathrm{S}-48^{\circ} \mathrm{W}\right)$ apresenta ambientes praiais do tipo dissipativo, com altura média de onda de 1 a 1,5 m (Gianinni et al. 2007). O sistema estuarino de
Laguna é composto por uma lagoa sufocada que abrange uma área de $184 \mathrm{~m}^{2}$ (Fonseca e Netto 2006). O complexo estuarino foi formado a partir das variações do nível relativo do mar oriundas do final do período Quaternário, sendo este sistema separado do oceano por uma barreira arenosa com extensos campos de dunas ao norte e a sul, onde no setor sul há uma intensificação da urbanização sobre os campos dunares (Fonseca \& Netto 2006).

\section{Observação de Campo}

As campanhas de campo para observação das feições geomorfológicas foram realizadas em agosto de 2013. As quais seguiram um padrão com base nas escalas espaço-temporais, seguindo da maior escala para a menor escala espaço-temporal (Fig. 2). Assim, primeiramente foi observado o contexto geral da região considerando sua gênese e tempo geológico de formação. Uma vez que o contexto havia sido compreendido, passou-se a observar os processos que ocorrem em menor escala temporal, visando identificar indícios de mudanças na dinâmica costeira, tanto devido a processos naturais quanto por ação antrópica. Os processos e formações geológicas de maior relevância foram registrados em fotografia científica para posterior consulta.

Em SFS foram visitados quatro pontos: Praia do Forte, Praia da Enseada, Prainha da Petrobras e Canal do Linguado, contemplando assim, três praias arenosas e um ponto de desembocadura,

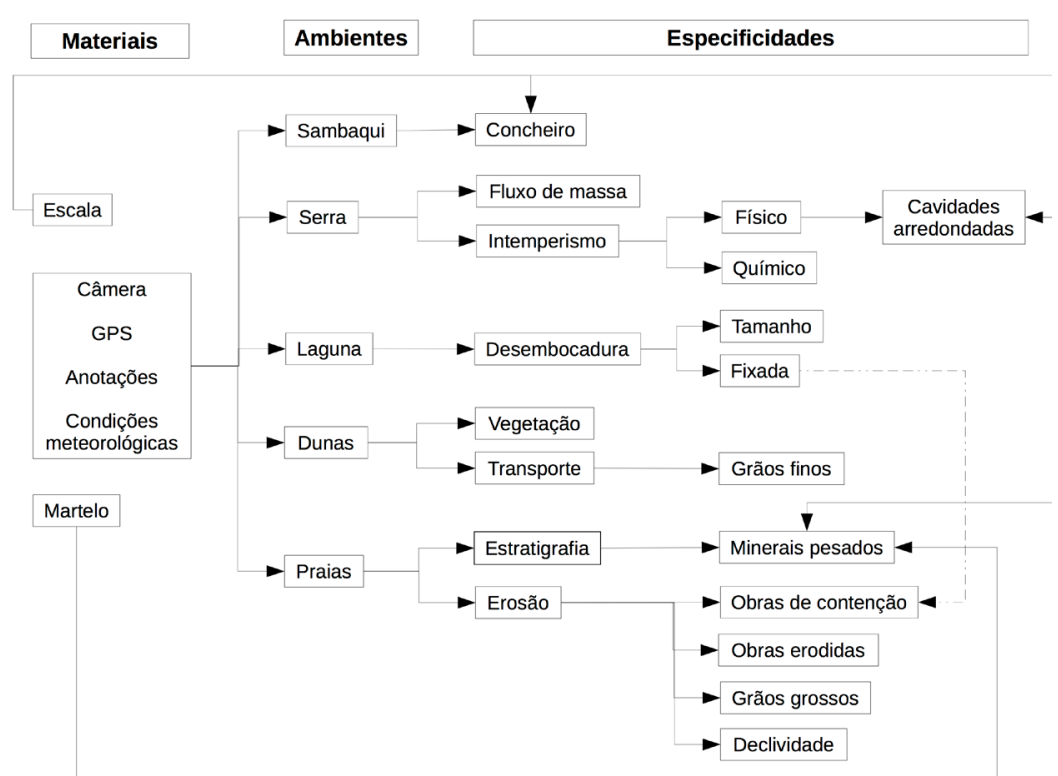

Figura 2. Fluxograma esquemático dos materiais utilizados nas análises observacionais, bem como os ambientes e feições analisados 
respectivamente. $\mathrm{Na}$ região sul do Estado foram observados os balneários BSB e PCS.

Em FLO buscou-se selecionar pontos com base no processo de sedimentação da região de maneira que todo o processo de formação sedimentar pudesse ser observado. Assim foram escolhidos: Mirante de Florianópolis, Lagoa da Conceição, Dunas da Joaquina e Praia da Joaquina. Em Itajaí foi realizado somente um ponto na Praia da Atalaia/ Desembocadura do rio Itajaí-Açú, a fim de analisar a interferência dos molhes nos processos de transporte e sedimentação.

O último município visitado foi LAG, tendo como pontos de observação as dunas da Galheta, subsequente à Praia da Galheta, a desembocadura dos Molhes e o Farol de Santa Marta.

\section{Resultados e Discussão}

$\mathrm{Na}$ costa do Estado de Santa Catarina, encontramos terrenos formados no período Holocênico que estão relacionados com a variação do nível do mar (NM) em cerca de $100 \mathrm{~m}$. O rebaixamento do NM aumentou o efeito da gravidade sobre os rios, intensificando seus aportes sedimentares nas áreas adjacentes inferiores e originando áreas de armadilhas sedimentares das partículas provenientes $\mathrm{da}$ Serra do Mar, como no caso de LAG e da Lagoa da Conceição, em FLO. O mesmo pode ter ocorrido com a diferença na conformação desse aporte sedimentar nas zonas de sombras de promontórios próximos a costas, originando a caracterização atual de ilhas, como por exemplo a Ilha de São Francisco do Sul (SFS).

Dentre as muitas feições observadas, algumas agem como Indicadores de Paleoníveis Marinhos (IPNM), que revelam a sua área de gênese e possibilitam a datação de sua formação. Um exemplo dessas feições são os sambaquis, como o encontrado em SFS (Fig. 3A) e em LAG. Outra feição que atua como IPNM encontrados são os resultados de atividade biológica registradas em rochas. Na Praia de Atalaia, em ITJ, foi possível observar cavidades circulares em costões rochosos que provavelmente são oriundas da fixação de equinodermos que causaram o desgaste da rocha, atuando, assim, como IPNM.

Os sedimentos transportados pelos rios são originados, majoritariamente, pelo processo de erosão e intemperismo das rochas e do solo. De acordo com Guerra \& Marçal (2006), o transporte do material proveniente das rochas e do solo é coletivamente originado pela força da gravidade, podendo ser potencializado, ou não, pela ação da água, o que caracteriza os fluxos de massa (e.g. deslizamento de terra). Após o desmembramento das partículas a partir destes fluxos, grande parte dos sedimentos tende a alcançar um meio aquoso (i.e rios), e, então, são transportados via fluvial até que estes alcancem a região litorânea. Devido à formação da Serra do Mar, grande parte dos rios fluem para o interior do continente. Em Santa Catarina, o rio de maior porte é o Itajaí-Açú (Fig. 1), o qual desemboca em Itajaí (Tessler \& Goya 2005). Embora não haja rios de grande porte ao longo do litoral de Santa Catarina, os pequenos rios que desaguam tanto diretamente no mar, quanto em estuários, desempenham um papel fundamental no aporte sedimentar nestas regiões, uma vez que a exportação de sedimentos nestas áreas torna-se limitada por estes pequenos cursos de descarga fluvial (Short \& Klein 2016).

Nesse contexto, no litoral sul de Santa Catarina, encontramos dois sistemas lagunares responsáveis pelo aporte de fluvial proveniente do continente: a Lagoa da Conceição que compõem o sistema lagunar em FLO, apresentando desembocaduras mais restritas; e o sistema lagunar de Laguna (LAG). Em FLO grande parte do aporte fluvial é proveniente do continente, servindo como uma armadilha de sedimento com profundidade média de 1,7 m (Muehe \& Caruso Gomes Jr. 1983).
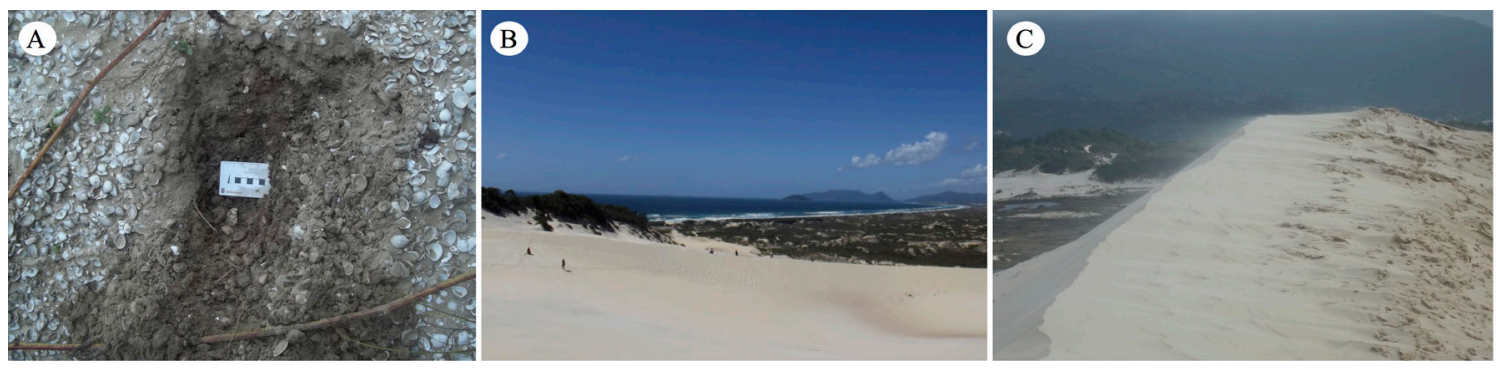

Figura 3. A - Sambaquis observados na praia de Fora em SFS. B - Dunas da Joaquina em FLO. C - Orientação do vento no campo dunar, localizados em FLO 
Como observado em campo, o regime de ventos regula a circulação costeira da Lagoa da Conceição localizado em FLO, sendo o principal responsável pelas ondulações e ressuspensão sedimentar e pela formação dos imensos campos de dunas encontrados na região (Fig. 3B e C).

As características de campos de dunas são proporcionais à competência do vento em movimentar o tamanho de grão de areia para que ele seja transportado e depositado dando início à sua formação (Fig. 3C). Deste modo, conhecer o regime de ventos e as características texturais dos sedimentos disponível na praia e nas dunas, é fundamental para analisar processos de migração de ambientes deposicionais eólicos (Vintem et al. 2003). Neste cenário de migração de campos de dunas é possível fazer uma conexão com o que foi observado in situ. As dunas da Galheta em LAG estão avançando em direção à área urbana, enquanto que em FLO, há a presença da restinga nas dunas da Joaquina, o que dificulta a migração para a região urbanizada. Porém, isso não significa que o campo de dunas não migra em seu território ou em direção contrária ao ambiente praial formando diferentes feições em escalas sazonais de tempo, como foi observado pela intrusão de material sedimentar nas vias públicas de transporte próximo à Lagoa da Conceição. Isso, portanto, é um bom indicador de que em algum momento o regime de ventos da região variou, o que permitiu o afloramento de vegetação próximo à praia da Joaquina e uma migração do campo de dunas em direção ao sistema lagunar da Lagoa da Conceição.

Dentre os agentes de transporte no ambiente marinho-costeiro, as correntes longitudinais são responsáveis pelo retrabalhamento e movimento dos sedimentos, principalmente na zona de surf, onde há grande quantidade de partículas em suspensão (Wright 1995). Essas correntes, também denominadas de deriva longitudinal, são um dos fatores físicos que modelam e entregam sedimentos à linha de costa. Em alguns casos, como na Praia do Forte em SFS, devido à necessidade de dragagem do canal navegável que dá acesso ao porto de São Francisco, houve uma modificação na área ao longo do tempo, o que refletiu no padrão de sedimentação e circulação da água. Atualmente, o atual esporão formado na região é fruto dessas alterações, responsável pelo excedente de sedimentos na plataforma. Posteriormente ao evento, a ação das forçantes físicas da região formou um esporão arenoso que se estende do promontório em dire- ção ao canal navegável, com aproximadamente 15 $\mathrm{m}$ de distância da linha de costa. A percepção da evolução do esporão da Praia do Forte evidenciou como os mecanismos de transporte naturalmente criam e desfazem feições geomorfológicas. Considerando isso, realça-se a necessidade de uma ampla compreensão da dinâmica dos mecanismos de transporte em ambientes costeiros durante a implantação de empreendimentos na orla, principalmente em relação às alterações na dinâmica de transporte sedimentar, os quais podem resultar em processos erosivos na área costeira (MMA 2006).

Também, pode-se observar que em SFS houve a modificação de parte da linha de costa do município. A construção do terminal marítimo da Petrobras tornou-se uma barreira para os sedimentos transportados via deriva longitudinal que seriam transportados para a Praia da Enseada. Este terminal pode ser um dos fatores da mudança na dinâmica de ondas da praia e na entrega de sedimentos pela deriva longitudinal, ocasionando erosão em sua parte central. Atualmente, os sedimentos barrados pela construção do terminal se acumularam e passaram a depositar e formaram uma praia artificial popularmente conhecida como "Prainha da Petrobras" (Fig. 4A).

Os processos de erosão ficaram mais evidentes nas observações feitas no Balneário Barra Sul (BBS), onde as obras de contenção (Fig. 4B) estavam sendo intemperizados e erodindo, indicando uma intensa atividade física de ondas. Por conseguinte, a topografia da praia se mostrou ser inclinada e sua granulometria composta por areia grossa. Ainda dentro das observações feitas no BBS, as alterações advindas do bloqueio do Canal do Linguado afetaram diretamente a área, pois houve um aumento na urbanização sobre os sedimentos inconsolidados de deposição recente e, consequentemente, acréscimo na taxa erosiva (Vieira 2012, Short \& Klein 2016). Além disso, a retirada da vegetação também contribuiu para a erosão costeira do balneário. Algumas medidas, como a construção de anteparos, foram tomadas a fim de retardar a erosão costeira. Entretanto, muitas residências tiveram de ser abandonadas, já que apresentavam condições extremas de desabamento e insalubridade.

Ainda no contexto alterações antrópicas em ambientes costeiros, no Balneário de Piçarras (PCS) foram observadas estruturas de engenharia costeira, como a construção da gabiões, enrocamentos construídos perpendicularmente à costa, 

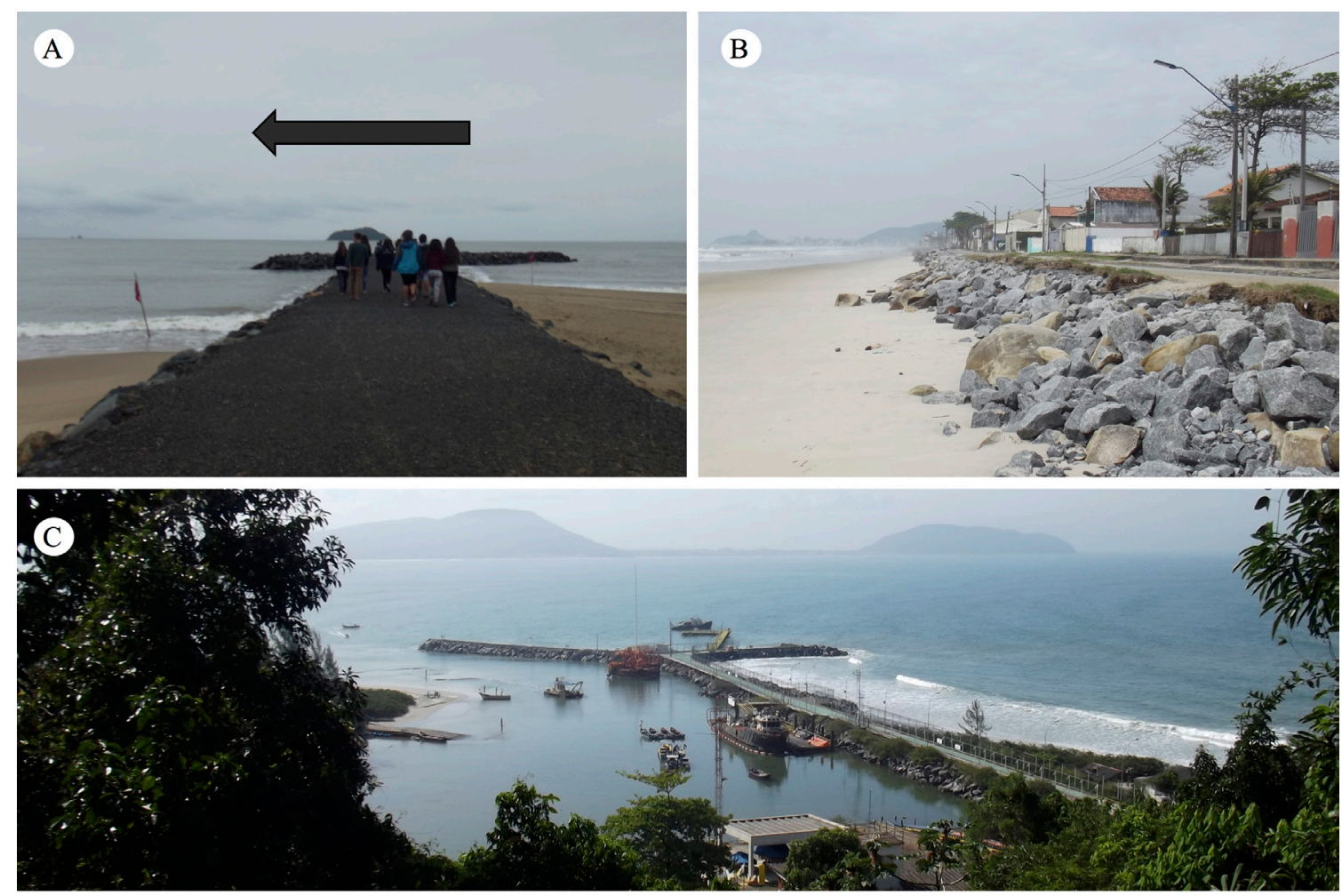

Figura 4. A - Terminal Marinho da Petrobras em São Francisco do Sul (SFS) que formou à direita da foto a prainha da Petrobras. B - Obras de contenção costeira no Balneário Barra Sul (BBS). C - Gabião no Balneário de Piçarras (PCS) barrando a deriva litorânea que seguiria na direção da indicada na seta da foto A, acumulando sedimento à direita e erodindo à esquerda do empreendimento.

a fim de conter a ação erosiva marinha (Fig. 4C). Visando uma maior durabilidade, alguns fragmentos do enrocamento estavam recobertos por geotêxtil, um produto permeável utilizado predominantemente na engenharia geotécnica, com funções de drenagem, filtração, reforço, separação e proteção. Entretanto, não foi previsto que esse tipo de construção barraria o transporte de sedimentos da deriva longitudinal ocasionando o aprisionamento de partículas em um lado da estrutura e erosão no lado subsequente. Por outro lado, no Balneário de Piçarras há uma intensa atividade erosiva em sua costa, em consequência disso era especulado a construção de, pelo menos, mais dois espigões. O objetivo desses espigões seria a redução da corrente de deriva litorânea e a estabilização do sedimento disposto em projetos de alimentação artificial da praia, ampliando o tempo de vida. Este processo consiste na introdução mecânica de uma imensa quantidade de sedimentos próximos à costa. Obras desse porte permitem que sistemas praiais erodidos se estabilizem ou ampliem, podendo resultar em criação de novas praias, como é o caso da "Prainha da Petrobras", em SFS.

A grande maioria dos enrocamentos analisados é composta por blocos rochosos. Apesar de ser resistente à erosão, com o passar do tempo pode haver o deslocamento e a quebra destes blocos, diminuindo a sua eficiência. $\mathrm{Na}$ desembocadura do Rio Itajaí-Açu, em Itajaí (ITJ), por exemplo, podemos observar a implantação de tetrápodes como obra de recuperação dos molhes Sul. Constituído em concreto maciço, o bloco é disposto de um eixo central, no qual são tangentes quatro "braços", distribuídos igualmente a $120^{\circ}$ no espaço. Estes "braços" facilitam a conexão entre os blocos, oferecendo maior estabilidade à estrutura. $\mathrm{O}$ centro de gravidade do tetrápode encontra-se na junção dos "braços", o que dificulta o balanço e o rolamento. Projetado para ser instalado em camada dupla, a utilização destes blocos diminui consideravelmente a energia das ondas e o nível da água que ultrapassa pelos interstícios (Migliorini et al. 2008). Com isso, a agitação das ondas no Porto de Itajaí torna-se inferior comparada ao mar aberto.

A extensão, morfologia e profundidade de uma desembocadura irá ser moldada conforme alguns fatores como o fluxo de descarga de energia fluvial que, juntamente com a força da maré e as correntes de deriva longitudinais, irão reger a dinâmica sedi- 
mentar das desembocaduras, levando ou não ao seu assoreamento ou à formação de esporões, que podem causar o fechamento da desembocadura. Devido a esse fato, algumas desembocaduras precisaram da construção de anteparos (enrocamentos) para controlar o seu assoreamento e deslocamento, pois são diariamente utilizados por embarcações de pequeno a médio porte

Na Praia do Forte, em SFS, a geomorfologia da região faz com que as ondas cheguem transversalmente à costa e transportem os sedimentos pela corrente de deriva longitudinal, os quais são depositados antes de chegar à praia, formando um esporão. Esse efeito de acúmulo de sedimentos ocorre pelo efeito do morro que funciona como zona de sombra sobre a praia. Também em SFS, o Canal do Linguado teve seu curso interrompido pela implantação da BR-280 em 1932, resultando na quebra da dinâmica fluvial do canal. Assim, o canal foi dividido em duas partes: o lado oeste à Baía da Babitonga, que atualmente recebe sedimentos da Serra Negra por via fluvial e que, após a divisão, perdeu a hidrodinâmica do local perdeu a influência das marés; e o lado leste, o qual apresenta uma dinâmica dominada pelas ondas e marés, tornando sua capacidade de deposição bem menor se comparada a porção oeste da Baía. As partículas que ficam sedimentadas na desembocadura do canal do Linguado são mais grossas do que aquelas retidas no setor oeste.

Na saída de campo também foram observadas diversas desembocaduras de rios e canais. Muitas dessas foram estabilizadas com a construção de molhes para que não migrassem ao longo do tempo, visto que são vias navegáveis de grande importância econômica, dentre os principais locais visitados podemos citar o Canal do Linguado (SFS) e a desembocadura da Lagoa da Conceição (FLO). O Canal do Linguado não apresenta grande aporte de sedimentos proveniente da Baía da Babitonga, devido à construção da BR-280. Por sua vez, a desembocadura da Lagoa da Conceição em FLO, apresenta dinâmica e fluxos intensos, porém, baixo aporte, uma vez que a lagoa atua como armadilha de sedimentos. Um processo semelhante pode ser observado na desembocadura de Molhes em Laguna que, assim como em Florianópolis, apresenta grande caudalosidade mas pouco aporte sedimentar pela presença da laguna como uma armadilha de sedimentos.

Diferenças nos tamanhos e tipos de desembocaduras são extremamente comuns, pois são reflexos da dinâmica a que estão submetidas. A desembocadura norte da Baía da Babitonga (SFS), a mais extensa visitada, não apresenta enrocamento e possui pequena profundidade, possuindo grande influência das marés. Esse ambiente pode ser colocado em contraponto com a desembocadura de molhes encontrada em LAG, pois apresenta um enrocamento de menor extensão, grande profundidade e fluxo forte, porém com maior influência de ondas do que de marés.

O enrocamento de desembocaduras é muito comum, já que tendem a migrar naturalmente com o tempo. Em diversos casos, como visto em FLO, na Lagoa da Conceição, o enrocamento ocasionou mudanças na dinâmica deposicional do ambiente, gerando áreas de erosão ao seu redor. Já na Praia da Atalaia, em ITJ, observamos um exemplo de enrocamento que não gerou consequências negativas no fluxo. Mesmo com a fixação da desembocadura, a dinâmica ao seu redor não foi afetada e a praia manteve sua configuração normal, fazendo com que as ondas continuem a atingir paralelamente a linha de costa.

Ambientes com estreita ligação entre o continente e o oceano, como estuários, lagunas e lagoas, apresentam um reflexo das forçantes que atuam neste meio. Os ambientes de sedimentação podem ter influência de maré, no caso dos estuários, ou de ondas, como em LAG e na Lagoa da Conceição, em FLO. Por possuírem desembocaduras mais restritas, esses ambientes acabam recebendo grande parte do aporte fluvial proveniente dos continentes, formando armadilhas de sedimentos de pequena profundidade.

Há ainda eventos de grande fluxo de massa que ocorrem episodicamente e são responsáveis por um superávit de aporte sedimentar, como as corridas de detritos, deslizamentos de encostas, entre outros. Em 2011, houve deslizamentos generalizados nas serras adjacentes às zonas costeiras, oriundo da grande pluviosidade registrada no início daquele ano, causando assim um grande aporte de partículas que são transportadas pelos rios até as zonas costeiras. Os agentes de transporte responsáveis pela movimentação e deposição dos sedimentos ao longo da planície costeira constroem as feições que observamos ao longo da costa. Assim, a má compreensão dos mecanismos de transporte em ambientes costeiros durante a implantação de empreendimentos na orla pode resultar em processos erosivos, principalmente devido à alteração na dinâmica dos fluxos. 


\section{Considerações Finais}

Neste trabalho, foi evidenciada a importância de se dispor de informações prévias sobre as feições geomorfológicas no ambiente costeiro antes de qualquer atividade antrópica. A partir das observações de campo foi possível perceber que os ambientes litorâneos não atuam isoladamente, mas sim como um conjunto de processos que modelam a linha de costa em uma complexa teia semelhante ao efeito dominó. Mudanças na geomorfologia costeira podem ocorrer em pequenas escalas de tempo ou paulatinamente dentro de milhares de anos, e a falta de preparo e conhecimento para se adequar à essas mudanças podem gerar perdas econômicas, assim como colocar vidas em risco. De qualquer modo, os ambientes praiais são os que respondem mais rapidamente às perturbações introduzidas, sejam elas de ordem natural ou relacionadas à ocupação (Castilhos 1995).

É extremamente importante a compreensão da dinâmica de transformação para uma formulação de estratégias de urbanização com manejo sustentável e gerenciamento adequado dessas áreas, visto que $70 \%$ da população mundial vive nos primeiros 300 $\mathrm{km}$ da orla costeira (Muehe 2006). Em diversas praias, observamos a construção de anteparos para conter a erosão ocasionada por mudanças na geomorfologia costeira, como por exemplo, os molhes. No entanto, tais estruturas modificam a dinâmica costeira, acarretando o acúmulo sedimentar em determinadas áreas e erodindo outras, agindo apenas como solução temporária para o problema. Assim, estruturas que foram construídas sem essa compreensão geral da dinâmica costeira, do transporte de sedimentos e contexto oceanográfico da região, colocaram praias que não estavam erodindo naturalmente em um contexto de erosão intensa, como ocorrido em BBS e PCS. Outra estratégia utilizada para tentar reverter o processo de erosão praial são engordas de praias. Este processo é menos agressivo do que a construção de molhes, no entanto, também altera a dinâmica sedimentar da região.

A erosão costeira é um processo natural, tornando-se um problema apenas quando a região possui valor econômico e estético, podendo ser agravada pela ocupação antrópica mal planejada e desenfreada, manifestando-se em construções sobre a vegetação costeira, em ambientes dunares e praiais ou mesmo próximas a desembocaduras de rios e estuários. Os problemas e perdas econômicas ocasionados pela erosão costeira e agravados pela ocupação desenfreada observados no litoral de Santa Catarina, são mais um indicativo de que a compreensão amplas dos diversos processos oceanográficos e geomorfológicos devem proceder estudos práticos e a implementação de empreendimentos na zona costeira.

Os estudos observacionais proporcionam uma ampla visão dos processos geomorfológicos de pequena e média escala. Portanto, estudos deste cunho, principalmente quando realizados em larga escala temporal, se mostram como ferramentas de grande importância para entender a evolução e gestão das zonas costeiras. Por fim, espera-se que esse trabalho contribua para futuras pesquisas sobre o tema e que haja maior incentivo nos estudos de campo observacionais.

\section{Agradecimentos}

Agradecemos ao professor de Oceanografia Geológica, Prof. Dr. Marcelo Lamour, por organizar e tornar possível esta vivência de campo, e à Universidade Federal do Paraná pela disponibilização de recursos.

\section{Referências}

Andrade A.R., Baldo M.C., Nery J.T. 1999. Variabilidade sazonal da precipitação pluviométrica de Santa Catarina. Acta Scient. Tech., 21:923-928. DOI: http://dx.doi.org/10.4025/actascitechnol. v21i0.3164. Acesso 04.08.2017.

Angulo R.J., Pessenda L.C.R., Souza M.C.de. 2002. O significado das datações ao ${ }^{14} \mathrm{C}$ na reconstrução de paleoníveis marinhos e na evolução das barreiras quaternárias do litoral paranaense. Rev. Bras. Geoc., 32(1):95-106. URL: http://ppegeo.igc.usp.br/ index.php/rbg/article/view/10396/9840. Acesso 15.08.2017.

Araujo R.S., Sprovieri F.C., Freitas D., Klein A.H.F. 2010. Variação da morfologia praial e identificação de zonas de erosão acentuada (ZEA) na Enseada do Itapocorói-SC. Braz. Jour. Aquat. Sci. Tech., 14(1):29-38. DOI: http://dx.doi.org/10.14210/ bjast.v14n1.p-29-38. Acesso 04.08.2017.

Becker B.K., 2001. Políticas e planejamento do turismo no Brasil. Cader. Virt. Tur. 1(1):1-7p. URL: http:// www.ivt.coppe.ufrj.br/caderno/index.php/ caderno/article/view/2/1. Acesso 28.08.2017.

Bessa F., Gonçalves S.C., Franco J.N., André J.N., Cunha P.P., Marques J.C. 2014. Temporal changes in macrofauna as response indicator to potential human pressures on sandy beaches. Ecol. Indic., 41:49-57. DOI: https://doi.org/10.1016/j. ecolind.2014.01.023. Acesso 04.08.2017.

Bortoluzzi C.A. 1987. Esboço geomorfológico de Santa 
Catarina. In: Silva L.C.da, Bortoluzzi C.A. eds. 1987. Texto explicativo para o mapa geológico do estado de Santa Catarina, E: 1:500.00. Florianópolis: Série Textos Básicos de Geologia e Recursos Minerais de Santa Catarina. N1. Series: Mapas e Cartas Sínteses, 3, Seção Geologia, 3. DNPM/SC. pp 133-167.

Castilhos J.A.D. 1995. Estudo evolutivo, sedimentológico e morfodinâmico da planície costeira e Praia da ArmaçãoIlha de Santa Catarina, SC. Florianópolis: Progr. PósGrad. Geografia. Univ. Fed. Santa Catarina. 134p. (Dissert. Mestrado). URL: https://repositorio. ufsc.br/xmlui/handle/123456789/76302. Acesso 09.08.2017.

Chaves T.F. 2016. Uma análise dos principais impactos ambientais verificados no Estado de Santa Catarina. Rev. Ges. Sust. Amb. 5(2):611-634. DOI: http://dx.doi.org/10.19177/rgsa.v5e22016611-634. Acesso 04.08.2017.

Coan B.D.P., Back Á.J., Bonetti A.V. 2015. Precipitação mensal e anual provável no Estado de Santa Catarina. Rev. Bras. Climat., 15:122-142. DOI: http://dx.doi.org/10.5380/abclima.v15i0.38348. Acesso 23.02.2018.

Fonseca G., Netto S.A. 2006. Shallow sublittoral benthic communities of the Laguna estuarine system, South Brazil. Braz. Jour. Ocea., 54(1):4154. DOI: http://dx.doi.org/10.1590/S167987592006000100004. Acesso 04.08.2017.

Fookes P.G., Baynes F.J., Hutchinson J.N. 2000. Total geological history: a model approach to the anticipation, observation and understanding of site conditions. In ISRM International Symposium. International Society for Rock Mechanics. URL: https://www.geplus.co.uk/Journals/2015/04/20/1/ c/z/2001-03 Pages 42-47.pdf. Acesso: 04.07.2017.

Giannini P.C., Sawakuchi A.O., Martinho C.T., Tatumi S.H. 2007. Eolian depositional episodes controlled by Late Quaternary relative sea level changes on the Imbituba-Laguna coast (southern Brazil). Marin. Geo, 237(3):143-168. DOI: https:// doi.org/10.1016/j.margeo.2006.10.027. Acesso 14.08.2017.

Guerra A.J.T., Marçal M.S.dos. 2006. Geomorfologia Ambiental. Rio de Janeiro: Bertrand Brasil. 93$149 \mathrm{p}$.

Júnior F.C., Muebe D. 1989. Batimetria e algumas considerações sobre a evolução geológica da Lagoa da Conceição-Ilha de Santa Catarina. Geosul, 4(7)32-44. URL: https://periodicos.ufsc.br/index. php/geosul/article/view/12724/11893. Acesso 31.10.2017.

Lins-de-Barros F.M. 2005. Risco, vulnerabilidade física à erosão costeira e impactos sócio-econômicos na orla urbanizada do município de Maricá, Rio de Janeiro. Rev. Bras. Geomorf., 6(2):83-90. DOI: http://dx.doi.org/10.20502/rbg.v6i2.54. Acesso 31.8.2017.

Migliorini A.V., Guimarães A.T.D.C. 2008. Tipo de blocos de concreto para estrutura hidráulica de proteção às ondas marinhas e análise visual dos tetrápodes da Barra de Rio Grande. III Seminário e Workshop em Engenharia Oceânica, Editora da FURG, Rio Grande, RS, 2008. URL: http:// repositorio.furg.br/handle/1/1423. Acesso 30.08.2017.

Mills J.P., Buckley S.J., Mitchell H.L., Clarke P.J., Edwards S.J. 2005. A geomatics data integration technique for coastal change monitoring. Earth Surf. Proc. Landf, 30(6):651-664. DOI: https://doi. org/10.1002/esp.1165. Acesso 30.08.2017.

Monteiro M.A. 2001. Caracterização climática do estado de Santa Catarina: uma abordagem dos principais sistemas atmosféricos que atuam durante o ano. Geosul, 16(31):69-78. DOI: https:// doi.org/10.5007/\%25x. Acesso 30.08.2017.

Muehe D.C.E.H (eds). 2006. Erosão e progradação do litoral brasileiro. Brasília: Min. Meio Ambiente, MMA. 475p. URL: http://www.mma.gov.br/estruturas/sqa_ sigercom/_publicacao/78_publicacao12122008084856. pdf. Acesso 29.08.2017.

Oliveira U.R.D. 2009. Relações entre a morfodinâmica e a utilização em trechos da costa oceânica da Ilha de Santa Catarina, SC, Brasil. Florianópolis: Progr. Pós-Grad. Geografia. Univ. Fed. Santa Catarina. 222p. (Tese Doutorado). URL: http://repositorio. ufsc.br/xmlui/handle/123456789/92670. Acesso 30.08.2017.

Ortiz J.D., Rack F.R. 1999. Non-invasive sediment monitoring methods. in Reconstructing Ocean History. Boston: Springer. 343-380. DOI: https:// doi.org/10.1007/978-1-4615-4197-4_20. Acesso 30.08.2017.

Pereira R.M.F.A. 2003. Formação sócio-espacial do litoral de Santa Catarina (Brasil): gênese e transformações recentes. Geosul, 18(35): 99129. DOI: https://doi.org/10.5007/\%25x. Acesso 30.08.2017.

Porto Filho E. 1993. Sedimentologia e algumas considerações sobre a bioquímica dos sedimentos do fundo da Lagoa da Conceição, Itha de Santa Catarina. Florianópolis: Progr. Pós-Grad. Geografia. Univ. Fed. Santa Catarina. 343p. (Dissert. Mestrado). URL: http://repositorio.ufsc.br/xmlui/ handle/123456789/75853. Acesso 30.08.2017.

Possamai T.O.H., Vieira C.V., Horn Filho, N.O. 2011. Geologia costeira da Ilha de São Francisco do Sul, Santa Catarina.Recife: UFPE - DCG/NAPA, v. especial VIII SINAGEO, n. 2. Rev. Geog. (Recife), 27(2):.45- 58. URL: http://sie.unb.br/ugb/sinageo/8/2/17.pdf. Acesso 02.09.2017.

Reis A.F. 2013. Urbanidade, paisagem e meio ambiente: subsídios para análise e qualificação do processo de transformação ambiental do litoral catarinense. $V$ Seminario Internacional de Investigación en Urbanismo, Barcelona-Buenos Aires, junio 2013. Departament d'Urbanisme i Ordenació del Territori. Universitat Politècnica de Catalunya, 1700-1714. URL: http:// 
hdl.handle.net/2099/14866. Acesso 02.09.2017.

Rhoads B.L., Thorn C.E. 1996. Observation in geomorphology. The scientific nature of geomorphology, 21-56. $27^{\text {th }}$ Binghamton Symposium in Geomorphology.

Rodrigues M.L.G., Franco D., Sugahara S. 2004. Climatologia de frentes frias no litoral de Santa Catarina. Rev. Bras. Geof., 22(2):135151. DOI: http://dx.doi.org/10.1590/S0102261X2004000200004. Acesso 30.08.2017.

Ruggiero P., Voigt B., Kaminsky G. 2000. Beach monitoring for enhanced decision-making. In Coastal Society 17th Conference Coasts at the Millennium-Portland, Oregon, 516-524. URL: http:// nsgl.gso.uri.edu/oresu/oresuc00002/pdffiles/ papers/087.pdf. Acesso 04.09.2017.

Schettini C.A. 2002. Caracterização física do estuário do rio Itajaí-açu, SC. Rev. Bras. Recur. Hídri., 7(1):123142. DOI: http://dx.doi.org/10.21168/rbrh.v7n1. p123-142. Acesso 30.08.2017.

Short A. D., Klein, A. H. D. F. 2016. Brazilian Beach Systems. USA: Springer International Publishing. 611p.

Souza C.R.G. 2009. A erosão costeira e os desafios da gestão costeira no Brasil. Rev. Gest. Cost. Inte. Jour. Integ. Coast. Zone Manag. 9(1):17-37. DOI: http:// dx.doi.org/10.5894/rgci147. Acesso 30.08.2017.

Sperandio D.G., Gomes C.H., Borges N.P., Ceolin A.C. 2017. Geologia de campo como ferramenta para entender e decifrar o planeta Terra de forma prática. In: Salão Internacional de Ensino, Pesquisa e Extensão. Anais... Salão de Pesquisa, 8(2). URL: http://seer.unipampa.edu.br/index.php/siepe/ article/view/17977/6805. Acesso 10.09.2017.

Tessler M.G., Goya S.C. 2011. Processos costeiros condicionantes do litoral brasileiro. Rev. Depart. Geog. 17:11-23. DOI: http://dx.doi.org/10.7154/ RDG.2005.0017.0001. Acesso 30.08.2017.

Van Rijn L.C. 2011. Coastal erosion and control. Oce. Coast. Manag. 54(12):867-887. DOI: https://doi. org/10.1016/j.ocecoaman.2011.05.004. Acesso 30.08.2017.

Vieira C.V. 2008. Mapeamento geológico costeiro e evolução paleogeográfica do setor oriental da folha Garuva, nordeste de Santa Catarina, Brasil. Florianópolis: Univ. Fed. Santa Catarina. 172p. (Dissert. Mestrado). URL: http://repositorio.ufsc.br/xmlui/ handle/123456789/91528. Acesso 30.08.2017.

Vieira C.V., Horn Filho N.O., Bonetti C.V.D.H.C., Bonetti J. 2008. Caracterização morfosedimentar e setorização do complexo estuarino da Baía da Babitonga/SC. Bol. Paran. Geoc. 62:85-105. DOI: http://dx.doi.org/10.5380/geo.v62i0.12783. Acesso 30.08.2017.

Vintém G., Tomazelli L.J., Klein A.D.F. 2003. O Efeito do tamanho de grão de areia no processo de transporte eólico dos campos de dunas transgressivas do litoral do Estado de Santa Catarina, Brasil. In II Congresso sobre Planejamento e Gestão das Zonas Costeiras dos Países de Expressão Portuguesa. IX Congresso da Associação Brasileira de Estudos do Quaternário. II Congresso do Quaternário dos Países de Língua Ibéricas. Recife, (1). URL: http:// www.abequa.org.br/trabalhos/quatcost_246.pdf. Acesso 10.09.2017.

Wright L.D. 1995. Morphodynamics of inner continental shelves. Bosa Roca, USA: CRC Press Inc. 241p. 